\title{
Caracterização de microexsudações de hidrocarbonetos na Bacia do Tucano Norte (BA) por geoestatística, classificação hiperespectral e redes neurais
}

\author{
Talita Lammoglia ${ }^{1}$, Carlos Roberto de Souza Filho ${ }^{1} \&$ Raimundo Almeida Filho ${ }^{2}$
}

\begin{abstract}
Resumo Com base na análise estatística de dados geoquímicos regionais derivados de amostras de solo e no processamento digital de imagens dos sensores Enhanced Thematic plus (ETM+/Landsat7 satélite) e Advanced Spaceborne Thermal Emission and Reflection Radiometer (ASTER/Terra satélite), este trabalho objetiva a caracterização de microexsudações de hidrocarbonetos na Bacia do Tucano Norte (BA). O estudo incluiu a elaboração de um modelo teórico de detecção segundo o qual as anomalias gasosas (exsudações) indicadas pela gasometria devem coincidir com determinadas expressões superficiais, tais como descoloração de solos e rochas (i.e., redução de $\mathrm{Fe}^{3+}$ para $\mathrm{Fe}^{2+}$ ), marcadores geobotânicos, concentração de argilas (caulinita) e carbonatos (siderita). Estas evidências indiretas foram utilizadas em conjunto com dados de sensoriamento remoto e técnicas de extração de informações para detecção de pontos com maior favorabilidade à presença de exsudação de hidrocarbonetos na Bacia do Tucano. Os dados ETM+ foram processados segunda a técnica de pesudo-razões - uma adaptação da análise por principais componentes clássica. Os dados ASTER foram processados pelas técnicas Spectral Angle Mapper e Mixture Tuned Matched Filtering (usualmente aplicadas na classificação de dados hiperespectrais e que foram aqui adaptadas para uso em dados multiespectrais), bem como por uma abordagem pioneira baseada em três diferentes sistemas de redes neurais (Fuzzy Clustering, Radial Basis Functional Link Network e Probabilistic Neural Network). Com base nestas técnicas, foram mapeados diversos locais onde as feições previstas no modelo teórico de detecção coincidem com as anomalias geoquímicas. Ademais, foram revelados setores com características similares em regiões ainda sem dados gasométricos. Estes locais são alvos potenciais para presença de exsudações e possivelmente reservatórios de hidrocarbonetos. A pesquisa demonstrou o excelente potencial dos dados ASTER e metodologias de análise espectro-espacial de baixo custo para a exploração de hidrocarbonetos nas bacias continentais brasileiras.
\end{abstract}

Palavras-Chave: microexsudações de hidrocarbonetos, classificação hiperespectral, ASTER, Redes Neurais, Bacia do Tucano.

\begin{abstract}
Characterization of hydrocarbon microseepages in the Tucano Basin (BA) using geostatistics, hyperspectral classification and neural network analysis. This study focus on the characterization of hydrocarbon microseepages in the northern Tucano Basin (Bahia State, Brazil), using geostatistical analysis of regional hydrocarbon geochemical data yielded from soil samples and digital processing of Enhanced Thematic plus (ETM+/Landsat7 satellite) and Advanced Spaceborne Thermal Emission and Reflection Radiometer imagery (ASTER/Terra satellite). A theoretical detection model was devised for the study in which gas anomalies (seeps) indicated by hydrocarbon geochemistry should spatially match a number of surface expressions such as the presence of bleached soil and rocks (i.e., reduction of $\mathrm{Fe}^{3+}$ to $\mathrm{Fe}^{2+}$ ), geobotanical markers and concentration of specific clays (kaolinite) and carbonates (siderite). These indirect evidences were employed for the application of remote sensing data and information extraction techniques in order to locate sites more favorable to host hydrocarbon seeps in the Tucano Basin. The ETM+ data was processed through the pseudo-ratio technique - an adaptation of the classic principal components analysis. The ASTER data was processed through the Spectral Angle Mapper and the Mixture Tuned Matched Filtering (techniques commonly used for the classification of hyperspectral data; here adapted for multispectral data) and via a pioneer approach by means of three different neural network systems (Fuzzy Clustering, Radial Basis Functional Link Network, and Probabilistic Neural Network). The results showed that several sites where the features predicted in the detection model concurred with geochemical anomalies were mapped. Other sites with similar characteristics, but for which no geochemical data were available, were also revealed. These sites are taken as new potential targets for the presence of seeps and oil reservoirs. The research demonstrated the excellent potential of ASTER data and spectral-spatial methodologies for low-cost, onshore exploration of hydrocarbons in Brazil.
\end{abstract}

Keywords: hydrocarbon microseepage, hyperspectral classification, ASTER, neural network, Tucano Basin

1 - Universidade Estadual de Campinas, Campinas (SP), Brasil. E-mail: talita.lammoglia@ige.unicamp.br, beto@ige.unicamp.br

2 - Instituto Nacional de Pesquisas Espaciais, São José dos Campos (SP), Brasil. E-mail: rai@1tid.inpe.br 
INTRODUÇÃo As técnicas de sensoriamento remoto aplicadas como ferramenta de auxílio à pesquisa de hidrocarbonetos podem ser divididas naquelas com enfoques de escala regional e escala de detalhe. Na escala regional, explora-se a visão sinóptica de extensas áreas proporcionada por imagens orbitais que possibilitam a derivação de informações (espectro-mineralógicas, lineamentos, rede de drenagem). Estas informações podem ser integradas com dados provenientes de outras fontes, como geológicos, geoquímicos (e.g., gasometria), geofísicos (gravimetria, magnetometria, sísmica), etc, com o objetivo de reconhecer áreas potencialmente favoráveis à ocorrência de microexsudação de hidrocarbonetos. Resultados importantes sobre a aplicação de sensoriamento remoto na pesquisa petrolífera também têm sido obtidos através de estudos em escala de detalhe, com base na detecção espectral de feições ligadas a processos de microexsudação de hidrocarbonetos, as quais comumente ocorrem de forma correlacionada às feições estruturais, contatos litológicos e redes de drenagem.

A bacia do Tucano Norte (BA), em especial a região da Serra do Tonã, vem sendo avaliada em pesquisas recentes quanto à ocorrência de exsudação de hidrocarbonetos. Relevantes resultados em exploração petrolífera obtidos nessa região, até o presente, incluem a caracterização de anomalias de hidrocarbonetos leves em superfície por geoquímica (Babinski et al. inédito) e por sensoriamento remoto, tanto em escala regional, como em escala de detalhe (Almeida-Filho 1999, 2001, 2002a,b,c). Em que pesem os esforços anteriores, nenhum estudo foi realizado até hoje na bacia Tucano Norte com base em dados hiperespectrais ou em dados de maior resolução espectral, como aqueles gerados pelo sensor Advanced Spaceborne Thermal Emission and Reflection Radiometer (ASTER), a bordo da plataforma Terra.

Neste contexto, buscando uma melhor caracterização destas acumulações de hidrocarbonetos e avaliação do potencial de novas metodologias para reconhecê-las, a presente pesquisa tem como objetivo a caracterização de microexsudações de hidrocarbonetos na Bacia Tucano Norte. O trabalho tem enfoque regional, bem como na escala de detalhe, por meio do estudo geoestatístico de dados geoquímicos de superfície (gasometria), processamento clássico e hiperespectral de imagens dos sensores/satélites ETM+/Landsat e ASTER/Terra, além da classificação de dados ASTER/ Terra por três diferentes sistemas de redes neurais.

\footnotetext{
ÁREA DE ESTUDO - BACIA DO TUCANO NORTE (BA) A área de estudo está localizada na bacia do Tucano Norte, no nordeste do estado da Bahia (Fig. 1). Tal bacia apresenta altitude média de $400 \mathrm{~m}$, com destaque para o alto da Serra do Tonã, a qual representa um platô de extensão reduzida com expressão topográfica entre 500 e $600 \mathrm{~m}$. A drenagem de segunda ordem se apresenta em arranjo dendrítico e com direção paralela a da drenagem de primeira ordem. $\mathrm{Na}$ Serra do Tonã, em particular, a drenagem se distribui radialmente (Rolim 1984).
}

Inserida no semi-árido do Nordeste Brasileiro, a bacia do Tucano Norte apresenta baixa pluviosidade anual, com média de $583 \mathrm{~mm}$, e temperatura média de $26{ }^{\circ} \mathrm{C}$ (Almeida-Filho et al. 2002a, Araújo e Rodrigues 2005). O solo é arenoso e pobre em humos e a vegetação é de natureza xenofítica, do tipo caatinga (Rolim 1984).

A bacia do Tucano Norte representa um semigraben que pertence ao rifte do Recôncavo-TucanoJatobá, formado durante os estágios iniciais da abertura do Atlântico sul no Cretáceo Inferior como resposta a evolução de um braço abortado da ruptura continental. A orientação do rifte é N-NE, com abrupta terminação orientada a E-NE na sua porção norte (Barbosa \& Dominguez 1996, Milani \& Davison 1988, Magnavita et al. 2003).

Os litotipos que afloram na área de estudo pertencem majoritariamente à bacia do Tucano Norte, em especial à Formação Marizal e à Seqüência do Tonã, com exceção de restritos afloramentos de suítes magmáticas e gnaisses micaxistos, metagrauvacas, paragnaisses, migmatitos e ortognaisses do grupo Macururê e do Complexo Belém do São Francisco ao sudoeste da área (Rolim 1984, Almeida-Filho 2002b). A formação Marizal inclui conglomerados e arenitos conglomeráticos feldspáticos em sua base, além de intercalações irregulares e descontínuas de argilitos sílticos, calcários e folhelhos betuminosos (Rolim 1984, Barbosa \& Dominguez 1996). A seqüência do Tonã, depositada em conformidade sobre a formação Marizal, representa uma seqüência de intercalações de arenitos e calcário silicificado, sendo o topo composto pelo último (Almeida- Filho 2002b). As direções dos eixos de dobra na bacia do Tucano Norte são variáveis, indicando complexa fase de compressão obliqua para suas margens. Três conjuntos de falhas são proeminentes: N15E, N85E e N25W (Bueno et al. 1996).

EXSUDAÇÕES DE HIDROCARBONETOS EXsudações de hidrocarbonetos são expressões superficiais do escape de hidrocarbonetos, provenientes de uma fonte em sub-superfície, através de um caminho permeável que possibilite a sua fluência em função da flutuabilidade (Clarke \& Cleverly 1991). As mesmas podem ocorrer tanto em áreas continentais (on-shore) como marinhas (off-shore) e constituem evidências da presença de reservatórios de óleo e/ou gás em subsuperfície (Schumacher 2002). Todavia, não são indicadores suficientes para a classificação econômica de uma área (Thompson et al. 1994). Face à alta mobilidade dos gases, as microexsudações usualmente ocorrem próximas aos reservatórios, normalmente no seu topo, sendo bons vetores para o posicionamento da fonte de hidrocarbonetos (Thompson et al. 1994).

Os mecanismos fundamentais de microexsudação (exsudações gasosas) de hidrocarbonetos incluem (i) efusão de gases livres devido a altas pressões diferenciais nos reservatórios; (ii) difusão de gases, usualmente dissolvidos na água que migram verticalmente por rochas porosas; e (iii) movimento vertical de hidrocarbonetos de baixo peso molecular dissolvidos na 


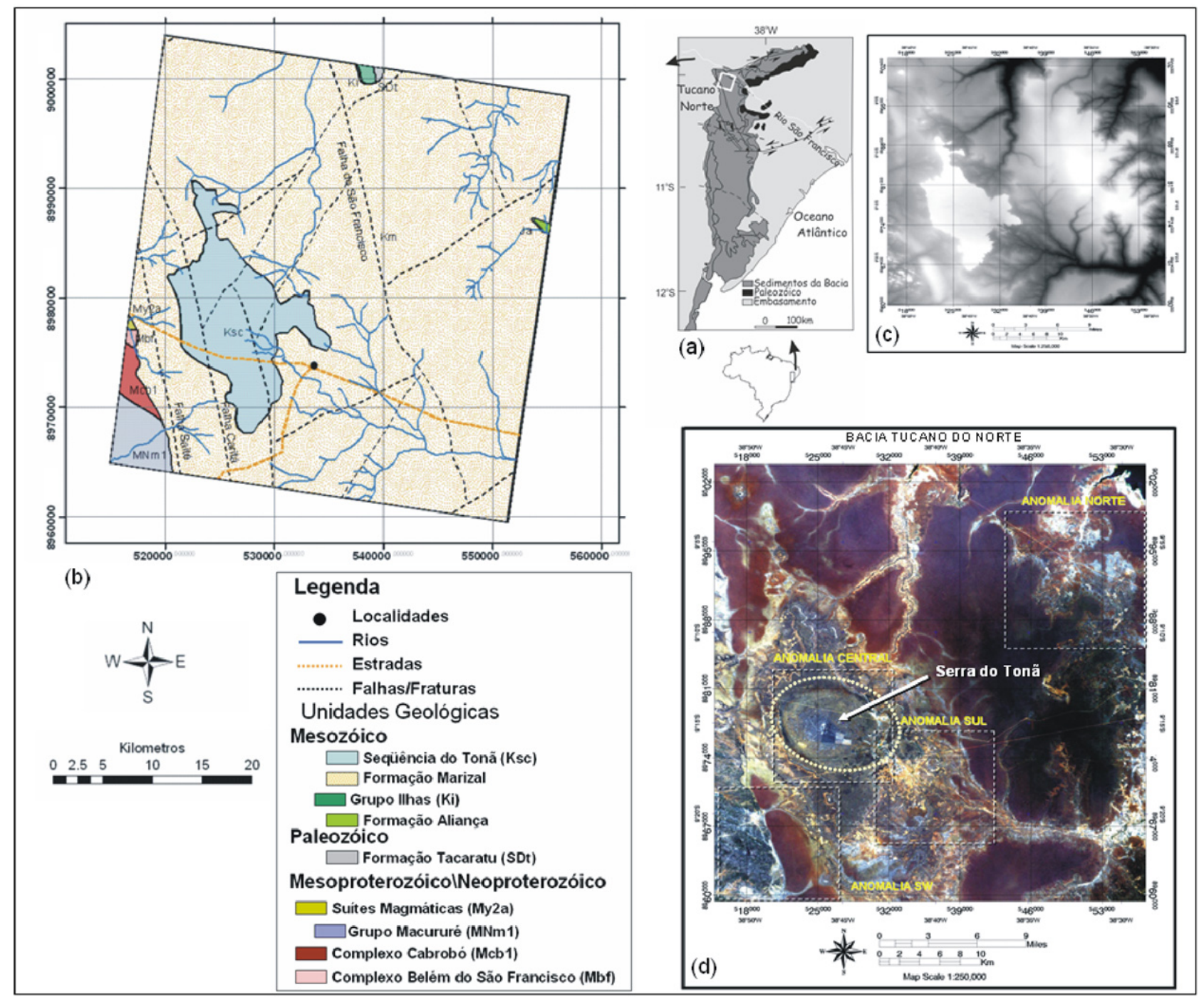

Figura 1 - Área de Estudo. (a) Localização e (b) mapa geológico (adaptado de Medeiros et al. (2000) e Magnavita et al. (2003)). (c) Modelo Digital de Elevação do Shuttle Radar Topographic Mission (SRTM). (d) Imagem Landsat

água, guiados pela diferença de potencial ou hidrodinâmica (Matthews 1986, Van der Meer et al. 2002). As microexsudações gasosas de hidrocarbonetos, basicamente compostas por metano $\left(\mathrm{CH}_{4}\right)$, etano $\left(\mathrm{C}_{2} \mathrm{H}_{6}\right)$, propano $\left(\mathrm{C}_{3} \mathrm{H}_{8}\right)$, butano $\left(\mathrm{C}_{4} \mathrm{H}_{10}\right)$ e pentano $\left(\mathrm{C}_{5} \mathrm{H}_{12}\right)$, podem produzir alterações em rochas, solos e vegetação (e.g., Schumacher 1996, Oliveira 1998).

MODELO TEÓRICO DE DETECÇÃO DE EXSUDAÇÕES DE HIDROCARBONETOS POR SENSORIAMENTO REMOTO A interação de hidrocarbonetos gasosos com o material da coluna estratigráfica gera, em superfície, uma ampla variedade de alterações de natureza física, química, mineralógica, botânica e microbiológica. Dentre essas, as de maior interesse para sensoriamento remoto são descritas abaixo.

Bleaching O fenômeno de bleaching (ou descoloração) é uma das manifestações típicas em áreas de microexsudação de hidrocarbonetos. Rochas sedimentares e solos tipicamente vermelhos que afloram sobre campos de petróleo têm sua cor alterada para cinza e castanho (e.g., Donovan 1979, 1986, Oliveira 1998). A perda da coloração avermelhada desses materiais ocorre quando soluções ácido-redutoras, tendo hidrocarbonetos, $\mathrm{H}_{2} \mathrm{~S}$ e $\mathrm{CO}_{2}$ como agentes principais, agem removendo o íon férrico $\left(\mathrm{Fe}^{3+}\right.$ - solúvel em ambiente redutor) originalmente presente na hematita, goethita e outros minerais limoníticos. Em muitos casos, o íon férrico pode ser convertido para íon ferroso $\left(\mathrm{Fe}^{2+}\right)$, favorecendo a formação de pirita e siderita (Schumacher 1996, Van der Meer et al. 2002).

$\mathrm{O}$ efeito bleaching pode ser detectado de duas formas: (1) pela mudança do comportamento espectral da rocha/solo na região do visível do espectro eletromagnético (EEM) em função da perda do conteúdo de $\mathrm{Fe}^{3+}$ nestes alvos. A hematita, goethita e limonita têm respostas espectrais caracteristicamente decrescentes da radiação vermelha para a radiação azul. Uma vez que o ambiente redutor causado pela microexsudação 
de hidrocarbonetos tende a remover esses minerais, observa-se decréscimo acentuado do gradiente de reflectância no visível, tal qual pode ser observado na figura 2; (2) pela mudança do comportamento espectral da rocha/solo na região do visível e do infravermelho próximo do EEM, porém em função da substituição de minerais portadores do Fe férrico (goethita, hematita) por minerais portadores de Fe ferroso (siderita, jarosita).

Argilo-Minerais A produção de $\mathrm{CO}_{2}, \mathrm{H}_{2} \mathrm{~S}$ e ácidos orgânicos resultantes da oxidação microbial de hidrocarbonetos $(\mathrm{HCs})$ próximos à superfície gera um ambiente redutor e levemente ácido capaz de promover alterações diagenéticas de feldspatos em minerais do grupo das argilas, incluindo caulinita, ilita e clorita (Schumacher 1996). A caulinita $\left(\mathrm{Al}_{4}\left[\mathrm{SiO}_{10}\right](\mathrm{OH})_{8}\right)$ pode ser caracterizada espectralmente por suas feições diagnósticas de absorção na região do infravermelho de ondas curtas (1,40-1,42 $\mu \mathrm{m}$ e 2,162-2,206 $\mu \mathrm{m})$ (Fig. 3). Vale ressaltar que, quanto maior a cristalinidade e/ou a abundância relativa desse mineral, mais marcadas serão suas feições espectrais diagnósticas (Pontual et al. 1997). O comportamento espectral característico de argilo-minerais também pode aparecer mais realçado no solo em função do efeito secundário de bleaching, pois conforme o alto conteúdo de Fe-férrico é eliminado do solo, as feições de absorção de argilas contidas nesses

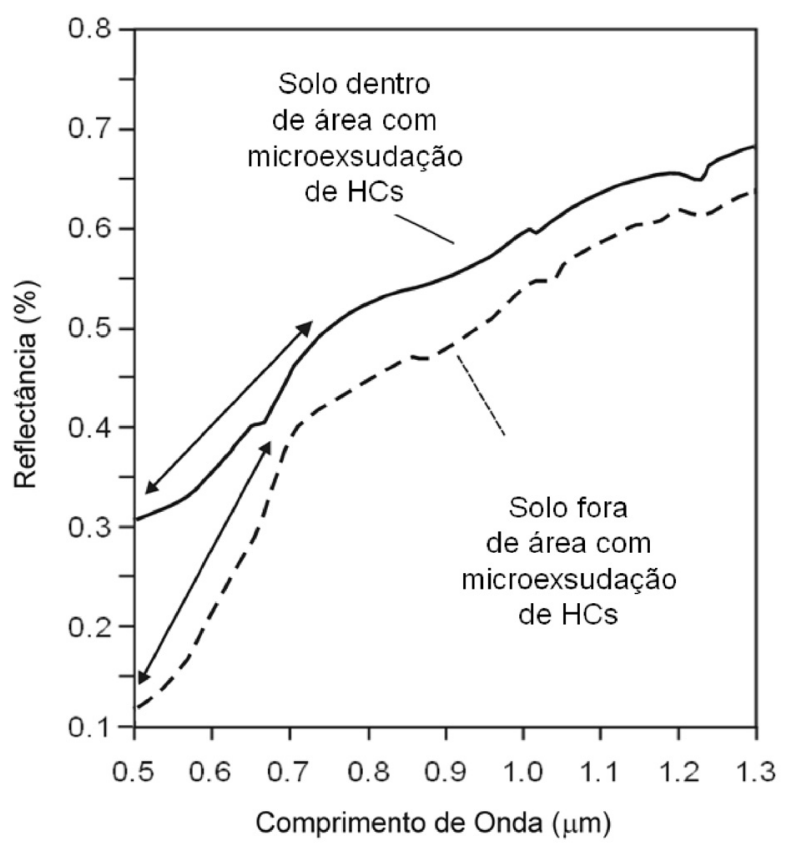

Figura 2 - Curvas de comportamento espectral de solos dentro e fora de área de microexsudação de hidrocarbonetos na área de estudo. As curvas indicam o efeito de bleaching na porção do visivel do espectro, com decréscimo acentuado do gradiente de reflectância entre o visivel vermelho e o visivel verde-azul.

solos podem se tornar mais evidentes.

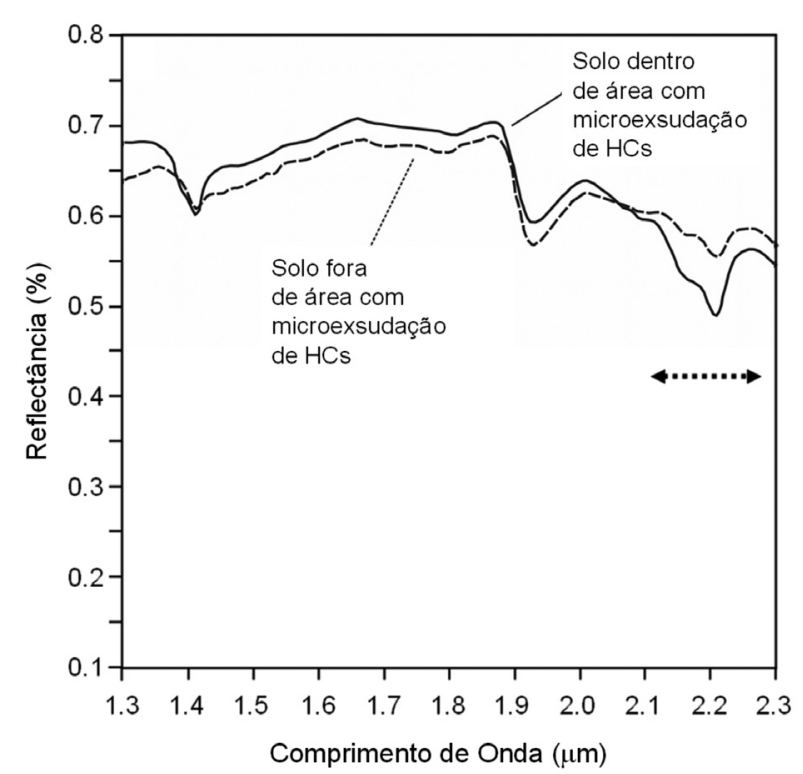

Figura 3 - Curvas de reflectância espectral de solos dentro e fora de zonas de microexsudação de hidrocarbonetos na área de estudo. As curvas indicam a maior abundância de caulinita (ou a presença de caulinita com maior cristalinidade) na zona com microexsudação de hicrocarbonetos, marcada pelo evidente doublet centrado em 2,2 $4 \mathrm{~m}$ e pela maior profundidade das feições de absorção nessa região.

Carbonatos Carbonato diagenético e cimento carbonático estão entre as alterações mais comuns em ambientes com microexsudações de hidrocarbonetos, induzidas pela oxidação química e/ou conversão bacteriológica pela ação de hidrocarbonetos e gases associados. Preenchimento dos poros por calcita e substituição por calcita são mais comuns na superfície devido à oxidação anaeróbica por bactérias redutoras de sulfetos ou por oxidação aeróbica (Klusman et al. 1992, Schumacher 1996). O cimento carbonático também pode ser gerado diretamente da redução inorgânica dos sulfatos (Van der Meer et al. 2002). Carbonatos portadores de Fe-ferroso $\left(\mathrm{Fe}^{2+}\right)$ em sua estrutura (e.g., siderita), também são observados em ambientes de microexsudações de $\mathrm{HCs}$, gerados a partir da solubilização do Fe férrico presente em outros minerais e incorporação subseqüente no carbonato (Van der Meer et al. 2002).

Anomalias geobotânicas A cobertura vegetal é sensível à toxidez do solo por hidrocarbonetos e compostos associados. Tais alterações comumente são marcadas por uma ou mais das seguintes feições: (i) ausência de vegetação, principalmente aquela fotossinteticamente ativa ('vegetação verde'); (ii) variações na densidade da flora; (iii) presença de plantas indicadoras, (iv) variações na arquitetura do dossel; e (v) mudanças morfológicas nas espécies. Esses efeitos, somados ou não, influenciam na resposta espectral da vegetação, principalmente no que se refere àquela relacionada ao pigmento clorofila, à es- 
trutura celular e à quantidade de água na planta (Augusto et al. 2005, Van der Meer et al. 2002).

Caracteristicamente, a vegetação sadia, fotossinteticamente ativa, apresenta curva espectral com pico de absorção em $0,48 \mu \mathrm{m}$ e $0,660 \mu \mathrm{m}$ e pico de reflectância em $0,55 \mu \mathrm{m}$ e em 0,75 $\mu \mathrm{m}$ (Drury 2001). Entre essas feições de absorção e reflectância ocorre o 'red edge', especificamente entre o ponto de inflexão do visível vermelho até o platô do infravermelho próximo. A vegetação sob estresse geoquímico induzido pela presença de hidrocarbonetos pode ser detectada remotamente, pois apresenta deslocamento do ponto de inflexão do 'red edge', seja para comprimentos de onda maiores ('red shift'), seja para comprimentos de onda menores ('blue shift'), devido a variações relacionadas à pigmentação das plantas. A vegetação submetida a estresse geoquímico também apresenta alteração em sua quantidade de água. Considerando estas alterações, Augusto et al. (2005) demonstraram que há uma inversão consistente do espectro da vegetação centrado nas faixas do infravermelho próximo (platô do NIR) e na primeira parte do infravermelho de ondas curtas $(\sim 1,65$ $\mu \mathrm{m})$ na medida em que a plantação cresce sob efeito de hidrocarbonetos.

No presente estudo, para efeito de simplificação, serão considerados alvos ideais de interesse: (i) áreas com alta concentração de hidrocarbonetos leves; (ii) áreas onde a vegetação fotossinteticamente ativa é ausente ou fortemente alterada; (iii) áreas onde superfícies ricas em Fe-férrico são ausentes ou pouco importantes; (iv) as áreas onde superfícies ricas em Fe-ferroso são presentes e destacáveis do 'background'; (v) áreas onde a concentração de argilas é importante, particularmente em caulinita. Os carbonatos, embora devam ser também considerados como alvos para indicação de microexsudaçõs de HCs, possuem ampla presença em rochas na área de estudo e serão, portanto, tratados eventualmente como indicadores complementares, mas não principais.

MATERIAIS E MÉTODOS Para o desenvolvimento da abordagem metodológica proposta, uma base de dados georreferenciada foi montada visando à detecção remota de alterações tonais e mineralógicas em solosrochas e anomalias na vegetação induzidas por microexsudação de hidrocarbonetos. A base compreende dados de geoquímica de hidrocarbonetos leves (gasometria) e dados de sensoriamento remoto orbital, além de medidas espectrais, obtidas em condições de laboratório, a partir de amostras coletadas no campo.

\section{Dados de geoquímica de hidrocarbonetos leves}

Para esse trabalho, conta-se com mais de seiscentas (>600) determinações de metano, etano, propano, butano e pentano em amostras de solo, coletadas a cerca de 1 metro de profundidade e espaçadas de $1 \mathrm{~km}$. As análises foram geradas pela PETROBRÁS, como resultado de um programa exploratório regional (Babinski et al. inédito).

Esses dados foram aqui utilizados de três formas básicas: (i) para avaliação da distribuição espacial de regiões com alta concentração de hidrocarbonetos em solo (seeps); (ii) como pontos de treinamento para a avaliação de assinaturas espectrais em imagens de sensoriamento; (iii) na aferição e validação dos resultados obtidos da interpretação dos dados de sensoriamento remoto, visando comprovar se informações discriminadas nas imagens têm sua origem relacionada aos processos de microexsudação de hidrocarbonetos.

Objetivando o entendimento da distribuição espacial dos diferentes hidrocarbonetos leves, os mesmos foram processados por técnicas geoestatísticas e interpolados por Krigagem com auxílio do programa ISATIS V5.1. (Burnaman et al. 1995, Olea 1995, Goovaerts 1997). A metodologia estatística incluiu a análise variográfica, a modelagem do semi-variograma com o modelo esférico e a interpolação por krigagem dos dados de gasometria. A krigagem é um algoritmo de interpolação que estima os valores para os nós da malha de forma que a diferença quadrática entre o nó da malha e os pontos circundantes seja consistente com o modelo do variograma. O objetivo deste algoritmo é buscar o melhor conjunto de ponderadores, de tal modo que a variância do erro seja a mínima possível (Chilès \& Delfiner 1999, Deustsch 2002).

Dados do sensor ETM+/Landsat-7 A cena ETM+ utilizada neste trabalho (ponto/órbita 216/66) foi adquirida em 30 de Setembro de 1999. Considerando a sua cobertura areal (185 x $185 \mathrm{~km})$, resolução espacial (15 a 60 metros) e espectral (7 bandas), esses dados foram utilizados para verificação regional de respostas tonais em relação às anomalias geoquímicas nas áreas alvo norte, sul e central (ver Fig. 6). O objetivo foi a detecção, dentro das possibilidades espectrais do sensor ETM+, de coberturas ricas em vegetação, compostos de ferro férrico e ferroso, argilas e carbonatos, conforme estabelecido no modelo de detecção de microexsudações para a área de estudo.

Os dados ETM+ foram processados com o uso da Análise por Componentes Principais (ACP), particularmente na sua versão de Componentes Principais Seletivas (Chavez \& Kwarteng 1989), e com as adequações propostas por Souza Filho \& Drury (1998). Essa técnica faz uso da ACP em pares de bandas e não requer correção atmosférica dos dados, nem da equalização de contraste entre as imagens. As bandas utilizadas para geração de pseudo-razões foram baseadas nas propostas de Buckingham \& Sommer (1983), Abrams et al. (1984), Prost (1980) e Hunt (1991) (Tab. 1).

Dados do sensor ASTER/Terra O sensor ASTER apresenta três sub-sistemas de imageamento independentes que cobrem o espectro-eletromagnético entre a região do visível e do infravermelho termal com resolução espectral de 15 bandas, resolução espacial de 15 a 90 metros e cobertura areal de aproximadamente $60 \mathrm{x}$ $60 \mathrm{~km}$ (Abrams et al. 2002). Os dados ASTER utilizados na pesquisa foram adquiridos da NASA no nível de processamento $1 \mathrm{~B}$ em 14 de maio de 2001 e estão circunscritos a imagem Landsat de órbita/ponto 216/66. 
Tabela 1 - Bandas ETM+ utilizadas para realce de materiais na área de estudo.

\begin{tabular}{l|l}
\multicolumn{1}{c}{ Material a ser realçado } & \multicolumn{1}{c}{ Landsat TM e ETM+ } \\
\hline Vegetação & TM4/TM3 \\
\hline $\mathrm{Fe}^{3+}$ (óxidos e hidróxidos) & TM3/TM1 (goethita) \\
\hline $\mathrm{Fe}^{2+}$ & $\mathrm{TM} 3 / \mathrm{TM} 2$ (hematita) \\
\hline Argilas e carbonatos & (TM2/TM3)+ (TM5/TM4) \\
\hline
\end{tabular}

PROCESSAMENTO DE DADOS DO SENSOR ASTER Pré-Processamento e processamento hiperespectral de dados ASTER Algumas bandas do sensor ASTER são invariavelmente afetadas pelo efeito de cross-talk causado pelo erro aditivo de reflectância devido ao redirecionamento de radiação incidente (Iwasaki et al. 2001). Para minimização desse efeito, foi aplicado, sobre os dados originais nível 1B, o algoritmo de correção do cross-talk disponibilizado pelo ERSDAC (2001). As bandas do infravermelho de ondas curtas foram também re-dimensionadas, quanto a sua resolução espacial, por um fator de $100 \%$, de forma a atingirem a resolução espacial de $15 \mathrm{~m}$ das bandas do visível e infravermelho próximo.

Neste estudo, a conversão dos dados ASTER em reflectância aparente na superfície foi feita utilizando-se o software Atmospheric Correction Now (ACORN), que envolve um cálculo da transferência radiativa baseada no modelo MODTRAN-4 (Imspec 2001). Para este propósito, os dados do nível 1B (valores de $\mathrm{DN}$ ) foram convertidos para dados calibrados em radiância no sensor $\left(\mathrm{W} / \mathrm{m}^{2} / \mathrm{sr} / \mu \mathrm{m}\right)$. Isso foi realizado multiplicando-se os pixels das imagens pelos coeficientes de conversão de cada banda individual, extraídos do arquivo HDF da cena ASTER. Em seguida, no sentido de maximizar o uso dos 256 níveis de cinza possibilitados pelos dados de 8 bits, um fator de ganho de 100 foi também aplicado às imagens convertidas para radiância. $\mathrm{O}$ uso do ACORN, utilizando-se os dados pré-processados, requereu também a especificação de alguns parâmetros, entre os quais, a localização da área; a elevação média do terreno; o posicionamento altimétrico do satélite Terra; data e horário de aquisição da imagem; funções de resposta espectral das bandas do ASTER; fatores de ganho e off-set do sensor; o modelo de correção atmosférica (tropical, latitude média no verão, inverno, etc); além de estimativas do vapor d'água e visibilidade atmosférica (aerossóis) no momento da aquisição dos dados. Esses dois últimos parâmetros são fundamentais para uma correção atmosférica exitosa das imagens e uma estimativa dos mesmos para este trabalho foi obtida a partir de dados do sensor MODIS, conforme método descrito em Souza Filho et al. (2007-submetido). A cena ASTER foi assim convertida para valores de reflectância aparente com base num modelo atmosférico tropical, $12 \mathrm{~mm}$ de vapor d'água e $80 \mathrm{~km}$ de visibilidade.
Previamente ao processamento para a extração de informação das imagens, aplicou-se uma máscara para a vegetação e para nuvens visando evitar interferência ou mistura entre materiais. A máscara para vegetação foi construída com base no NDVI (Normalized Difference Vegetation Index) (Rouse et al. 1974); a máscara para nuvens foi construída com base em parâmetros fornecidos pelos resultados da aplicação de classificação Spectral Angle Mapper com endmembers derivados das próprias nuvens.

A classificação hiperespectral, baseada em algoritmos originalmente desenvolvidos para o processamento de dados hiperespectrais, compreende a comparação entre a assinatura espectral de cada pixel da imagem, ou seja, de composição desconhecida, com a assinatura espectral de materiais de referência (endmembers). Muito embora desenvolvida para dados específicos, a classificação hiperespectral pode ser adaptada para dados multiespectrais de mais alta resolução espectral, como é o caso dos dados do ASTER, convertidos para reflectância. Em particular neste trabalho, a classificação hiperespectral foi realizada com bases em endmembers derivados de locais específicos de alta concentração de hidrocarbonetos determinados pela geoquímica. Adicionalmente, dentre medidas espectrais obtidas pelo espectrorradiometro FieldSpec-FR de 7 amostras coletadas dentro e fora da região central da anomalia sul, selecionou-se o espectro da amostra localizada no centro da anomalia, o qual foi utilizado como endmember nos experimentos de classificação.

A etapa de classificação envolveu um procedimento semi-automático, baseado, inicialmente, no uso seqüencial das técnicas Minimum Noise Fraction (MNF) e Pixel Purity Index (PPI) (Green et al. 1988, Boardman \& Kruse 1994), aplicadas as 9 bandas do ASTER convertidas para reflectância. Os endmembers foram selecionados a partir da inspeção de espectros extremos de pixels extraídos pelo PPI e projetados como pontos num visualizador n-dimensional contendo os eixos das imagens MNFs de maior ordem. A rotação interativa dos eixos das imagens MNFs e a observação dos pixels mais puros no espaço $n$-dimensional, permitiu a seleção de endmembers para serem utilizados nas etapas de classificação hiperespectral propriamente dita, através dos algoritmos Spectral Angle Mapper (SAM) (Kruse et al. 1993) e Mixture Tuned Matched Filtering (MTMF) (Boardman et al. 1995, Boardman 1998).

Classificação espectro-espacial de dados ASTER por redes neurais A classificação digital de dados ASTER por redes neurais teve por objetivo reconhecer padrões ocultos em pixels da cena ASTER da área de estudo, considerando a resolução espectral de nove bandas e a resolução espacial de 15 metros. As redes neurais representam um sistema computacional data driven, paralelo, distribuído e inspirado no raciocínio humano. Representam unidades dispostas em uma ou mais camadas e interligadas por links associados a pesos indicativos da força de cada conexão (Hewitson \& Crane 1994, Brown 2000, Nóbrega \& Souza-Filho 
2003, Rojas 2004).

As redes neurais são bastante apropriadas para o reconhecimento de padrões e classificação de dados espaciais devido: (i) a sua habilidade em extrair padrões ocultos em conjuntos de dados que podem ser imperceptíveis aos humanos e às técnicas estatísticas tradicionais; (ii) a capacidade de analisar dados sem nenhum conhecimento prévio sobre a sua distribuição; (iii) a possibilidade de trabalhar com dados ruidosos, limitados, interdependentes ou não-lineares; (iv) ao seu desempenho e rapidez, particularmente quando as feições do espaço têm características complexas e a fonte de dados tem diferente distribuição estatística; (v) a sua possibilidade de adição contínua de novos dados; (vi) e também a facilidade para análise de grandes conjuntos de dados (Hewitson \& Crane 1994, Brown 2000, Nóbrega \& Souza-Filho 2003, Roja 2004). Por possuírem tais qualidades, as redes neurais permitem que os dados ASTER sejam processados na sua forma bruta (nível 1B), sem necessidade de qualquer pré-processamento.

A classificação por redes neurais foi procedida utilizando-se o programa GeoXplore (Looney \& Yu 2000), que trabalha em combinação com o software ArcGIS, e seus três sistemas de treinamento e classificação de dados: Fuzzy Clustering (não supervisionado), Radial Basis Functional Link Network (RBFLN) e Probabilistic Neural Network (PNN) (supervisionados). Após o treinamento, qualquer destes três sistemas pode processar os vetores novos e desconhecidos a par- tir de fontes similares, e reconhecer as classes às quais pertencem (Fig. 4). O processamento dos dados incluiu a seleção das áreas de estudo, seguida pela combinação das nove bandas da cena ASTER para geração de um arquivo raster no ambiente do ArcGIS, possibilitando, assim, a entrada dos dados para processamento das redes neurais. Os pontos de treinamento utilizados foram os dados de gasometria de hidrocarbonetos leves (ie., etano $\left(\mathrm{C}_{2} \mathrm{H}_{6}\right)$, propano $\left(\mathrm{C}_{3} \mathrm{H}_{8}\right)$, butano $\left(\mathrm{C}_{4} \mathrm{H}_{10}\right)$ e pentano $\left(\mathrm{C}_{5} \mathrm{H}_{12}\right)$ somados). Para melhor classificação dos dados ASTER, efetuou-se também a fuzzificação dos pontos de treinamento através da função de pertinência fuzzy do tipo large (Looney \& Yu 2000). A pertinência reflete o grau de confiança da hipótese ou preposição, ou seja, grau de confiança na definição de anomalia ou não-anomalia baseado nas concentrações dos gases (Nóbrega \& Souza-Filho 2003). Uma vez que os dados foram preparados para entrada no processamento, a classificação foi realizada, através do módulo Geoxplore, pelos três diferentes sistemas disponíveis: (i) Fuzzy Clustering é um sistema bastante rápido de classificação não supervisionada por redes neurais. Este sistema não utiliza pontos de treinamento, pois o agrupamento é feito exclusivamente a partir dos dados. O agrupamento fuzzy é um bom método para ser utilizado quando as classes dos grupos se enquadram nos círculos de radianos fixos, uma vez que esse agrupamento é imune a anomalias numéricas (Looney \& Yu 2000); (ii) Radial Basis Functional Link Network (RBFLN) é um sistema de redes

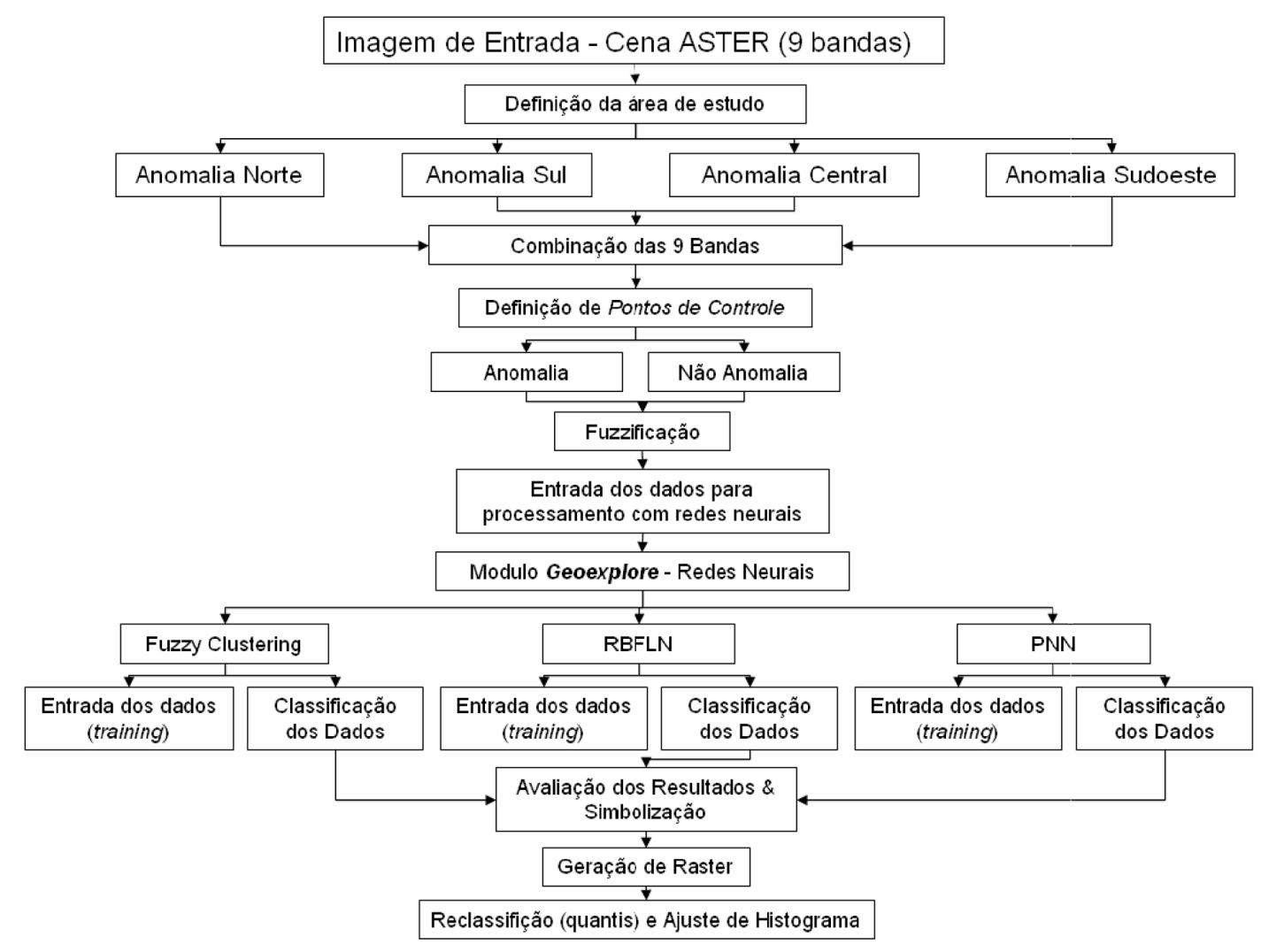

Figura 4 - Fluxograma das etapas seguidas para classificação digital da cena ASTER por redes neurais e geração de mapas de favorabilidade a presença de hidrocarbonetos. 
neurais que funciona de forma mais precisa e eficiente do que outras redes similares (e.g., Multi-Layer Perceptrons; Brown et al. 2000). Esse sistema requer pontos de treinamento tanto para regiões anômalas como para regiões não-anômalas e opera com três camadas: a de entrada, a intermediária e a de saída. Na camada de entrada, são ajustados e inseridos vetores-índice (feature vectors) para cada variável. Na camada intermediária, cada vetor é associado a uma função gaussiana de base radial, de modo que todos os vetores a distâncias iguais do centro apresentam o mesmo valor. Na camada de saída, todos os nodos (nodes) advindos da camada intermediária são combinados através de média ponderada, pois os pesos já foram ajustados (Looney \& Yu 2000, Roja 2004); (iii) Probabilistic Neural Network (PNN) é outro sistema de classificação supervisionada, porém este utiliza apenas pontos de treinamento das feições alvo, ou seja, das anomalias de hidrocarbonetos. A PNN, bem como a RBFLN, contém três layers de nodos: um de entrada, um intermediário e outro de saída. Cada nodo intermediário recebe as informações dos nodos de entrada e corresponde a uma função gaussiana centrada no vetor de entrada associado à determinada classe. Todas as gaussianas em uma classe alimentam, com seus valores de função, o mesmo nodo do layer de saída. No modo de saída todas as gaussianas da respectiva classe são somadas e compõem a função de densidade de probabilidade.

\section{RESULTADOS E DISCUSSÕES}

Resultados da krigagem de dados de gasometria $\mathrm{O}$ resultado da krigagem dos hidrocarbonetos exsudados $\left(\mathrm{C}_{2}-\mathrm{C}_{5}\right)$, sobreposto ao mapa geológico, pode ser observado na figura 5. A krigagem permitiu a discriminação das principais anomalias de hidrocarbonetos leves na área de estudo.

Para todos os gases estudados são observadas duas anomalias expressivas: a "anomalia norte" e a "anomalia sul". Há ainda uma anomalia mais suave, a sudoeste da área de estudo ("anomalia sudoeste"). As diferenças da distribuição espacial de concentrações de butano $\left(\mathrm{C}_{4} \mathrm{H}_{6}\right)$, etano $\left(\mathrm{C}_{2} \mathrm{H}_{10}\right)$ e pentano $\left(\mathrm{C}_{5} \mathrm{H}_{12}\right)$ podem ser mais facilmente notadas observando-se a figura 6 , que corresponde a uma composição colorida em RGB (Red/Green/Blue) das concentrações destes três gases. Nesta figura, nota-se que o butano e o pentano produzem algumas anomalias singulares ou combinadas entre si, com destaque para a anomalia identificada no centro da estrutura circular da Serra do Tonã ("anomalia central"). É interessante notar que, a exceção dessa anomalia central, praticamente todas as ocorrências anômalas de hidrocarbonetos, sejam singulares ou combinadas, estão associadas a drenagens e contatos litológicos na área de estudo (Fig. 5).

Resultados do processamento digital de imagens ETM+/LANDSAT-7 Os resultados ilustrados na figura 7 compreendem recortes da cena Landsat ETM+, processada regionalmente para o realce de superfícies ricas em ferro férrico (goethita, hematita), ferro ferroso,

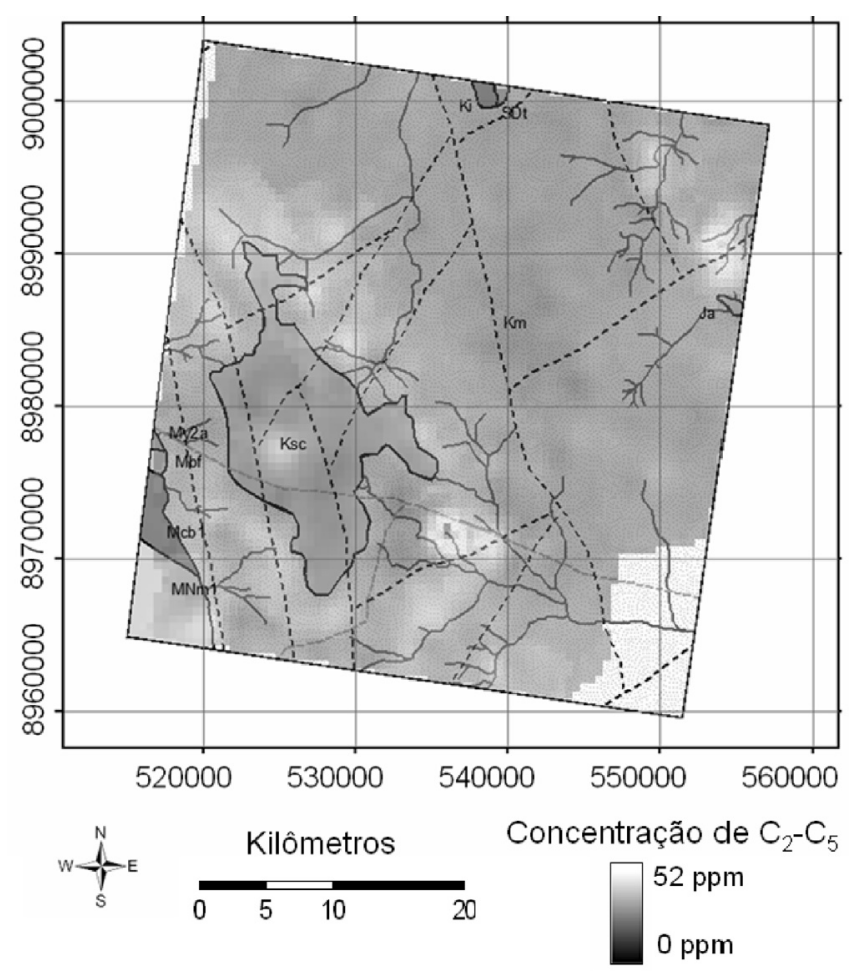

Figura 5 - Mapa geológico (cf. legenda na Fig. 1) sobreposto por concentrações de $C_{2}-C_{5}$ (anomalias combinadas). Notar a relação das principais anomalias (tons mais claros) com contatos litológicos e com a rede de drenagem.

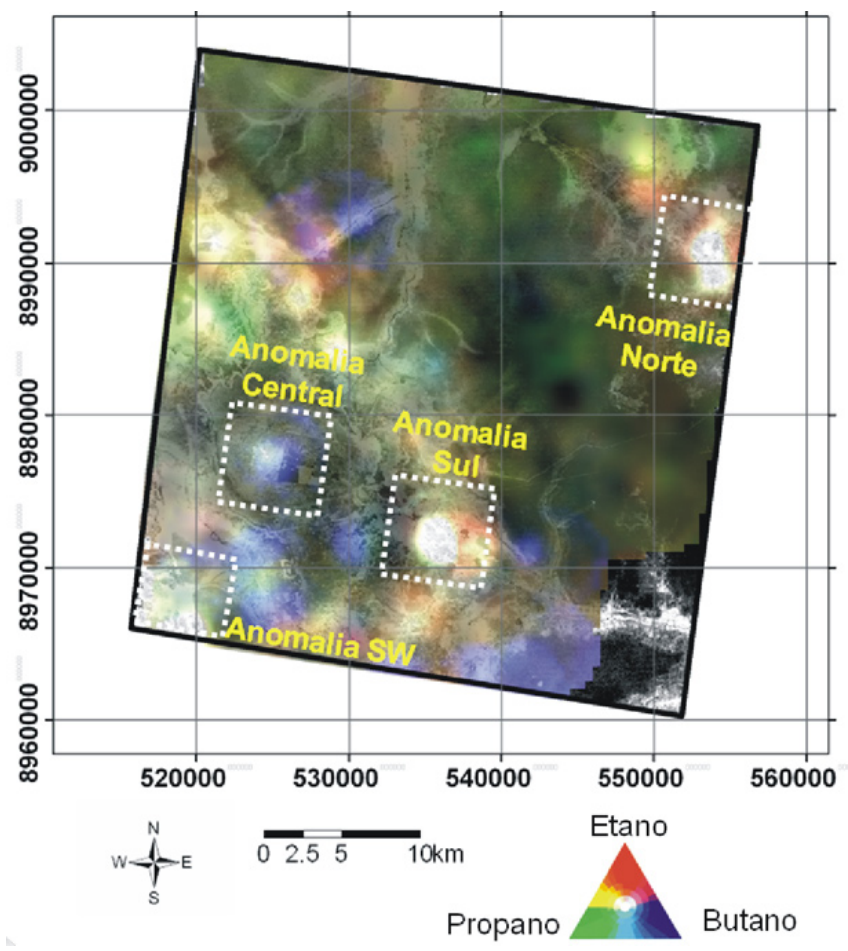

Figura 6 - Composição colorida $R G B$ gerada a partir dos mapas de concentração (superficies interpoladas) de butano $\left(C_{4}\right)$ em vermelho, etano $\left(C_{2}\right)$ em verde e pentano $\left(C_{5}\right)$ em azul, superpostas a imagem (banda 3) do sensor ASTER. 
argilas e vegetação, nas áreas das anomalias central, sul e norte.

Os resultados para todas as situações analisadas indicam que há marcante coincidência entre as zonas anômalas em $\mathrm{C}_{2}-\mathrm{C}_{5}$ e áreas ricas em $\mathrm{Fe}$-ferroso, ricas em argilas e/ou carbonatos, pobres em ferro férrico e desprovidas de vegetação - o que corrobora o modelo teórico de detecção de microexsudações de hidrocarbo-
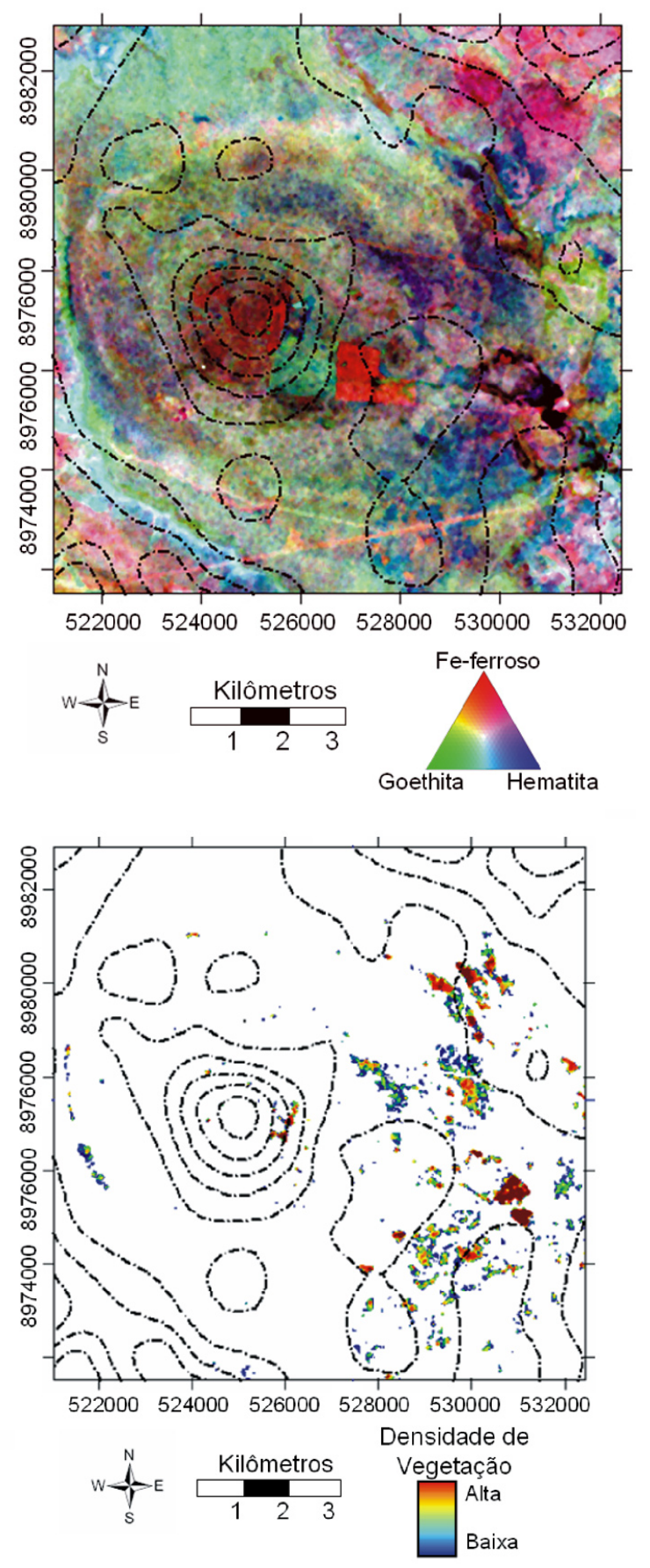

Figura 7 - Resultado da APC para a área central (veja Fig. 6). (a) (coluna esquerda, em cima) Composição colorida de superficies ricas em Fe-ferroso (R), Fe-férrico, com ênfase em goethita $(G)$ e Fe-férrico com ênfase em hematita (B). (b) (coluna da esquerda, em baixo) Imagem de densidade de vegetação fotossinteticamente ativa, em pseudo-cor (cores vermelhas e azuis indicam maior e menor densidade, respectivamente). (c) (coluna da direita, em baixo) Imagem de abundância de argilas e/ou carbonatos, em pseudo-cor (cores vermelhas e azuis indicam maior e menor abundância, respectivamente).

\section{Resultado do processamento digital de imagens AS- TER/Terra}

PROCESSAMENTO HIPERESPECTRAL Os resultados obtidos a partir do processamento dos dados do sensor $\mathrm{ETM}+$, os quais possibilitaram o reconhecimento das principais anomalias, não permitiram o mapeamento de mineralogias específicas, principalmente minerais do grupo da caulinita, que são de particular interesse para detecção das microexsudação de hidrocarbonetos. Assim, visando uma melhor classificação desta mineralogia em sub-áreas identificadas como anômalas com base nos dados de geoquímica e ETM+, a classificação hiperespectral foi procedida em imagem obtida pelo sensor ASTER que, por apresentar 6 bandas no infravermelho de ondas curtas, permite mapear caulinita ou outras argilas (e.g., Ducart et al. 2006). As áreas correspondentes às anomalias selecionadas estão discriminadas na figura 6 .

O espectro de referência utilizado para classificação da área sul foi derivado de amostra de campo coletada no centro da anomalia sul. Este espectro foi medido em condições de laboratório com o spectrometer FieldSpec-FR da Analytical Spectral Devices. Este espectro, comparado aos espectros de referência do USGS, apresenta feições diagnósticas de caulinita. Subordinadas diferenças entre os espectros devem-se a interferência na porção do infravermelho próximo causada pela presença de outros materiais na amostra de

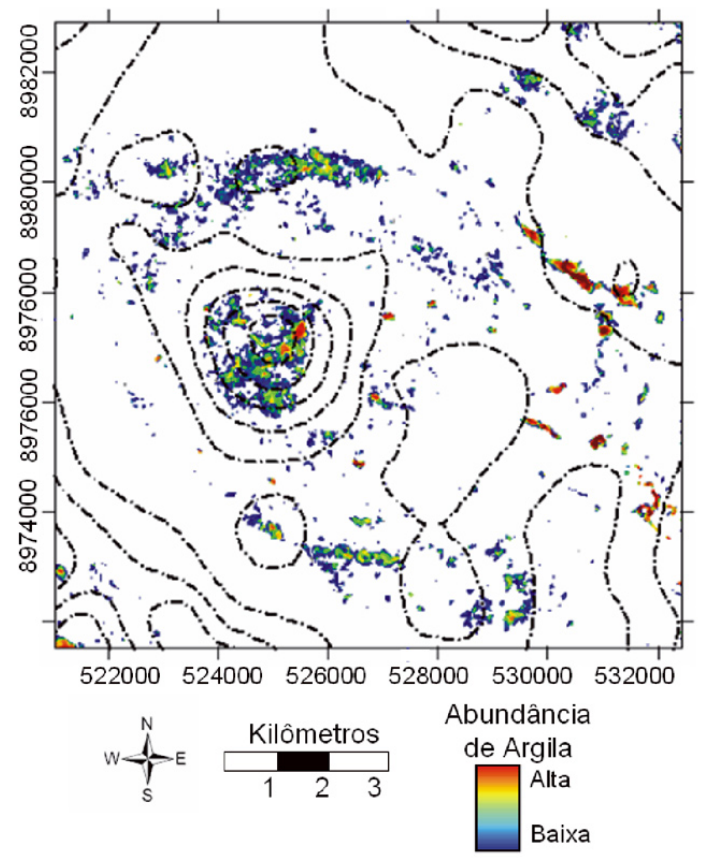


campo.

Os espectros de referência utilizados para a anomalia norte e central foram discriminados a partir da média da resposta espectral de pontos com alta concentração de hidrocarbonetos $\left(>30 \mathrm{ppm} \mathrm{C}_{2}-\mathrm{C}_{5}\right)$ nos respectivos cortes da cena ASTER. O espectro de referência utilizado é bastante similar ao espectro derivado de amostra de campo coletada no centro da anomalia sul, bem como ao espectro de referência de caulinita do USGS, exceto por variações subordinadas nas curvas devido, possivelmente, à interferência de outros materiais na assinatura dos pixels.

(a)

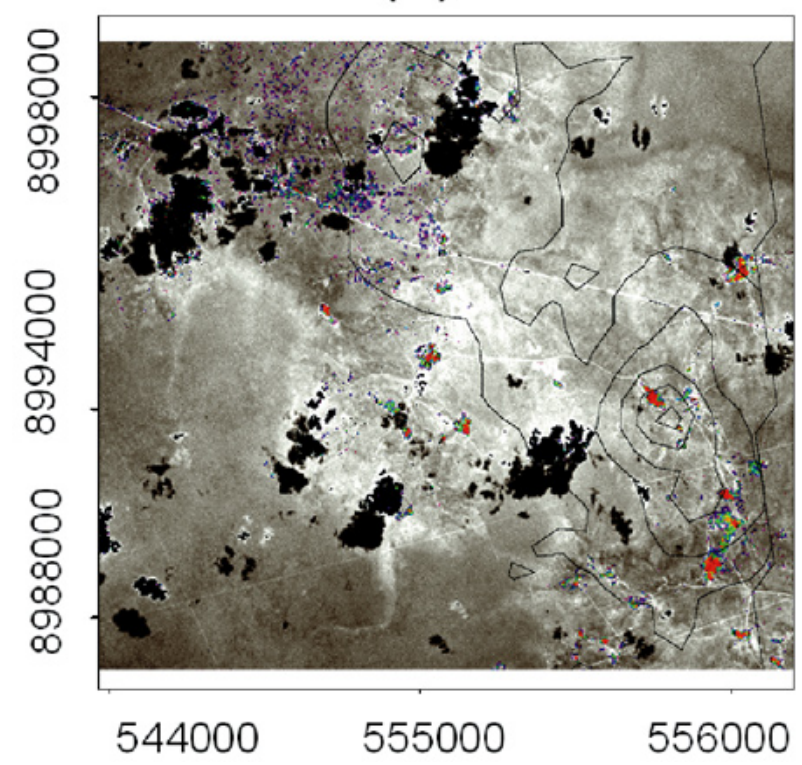

(c)

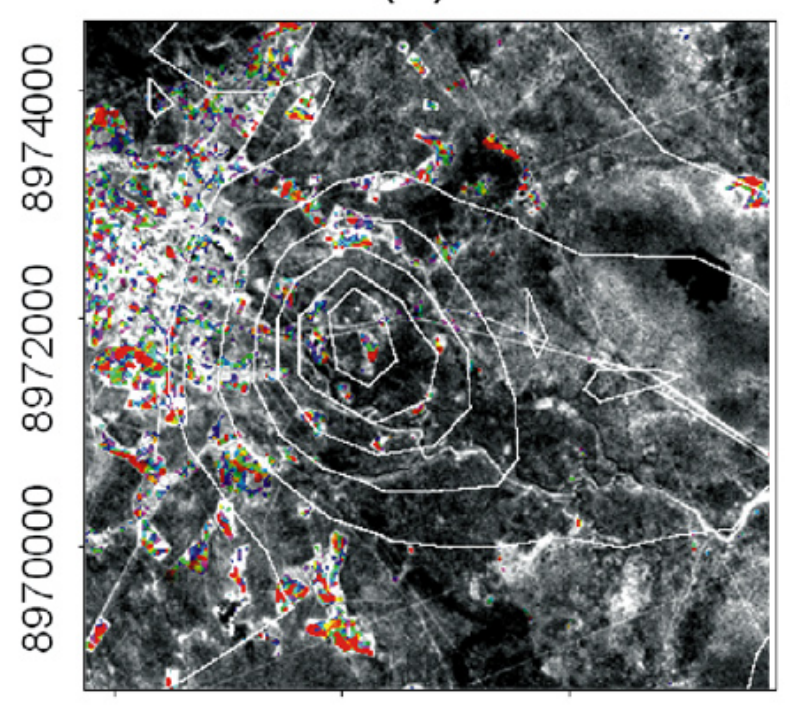

$534000 \quad 536000 \quad 538000$
Utilizando estes espectros de referência, as áreas anômalas foram classificadas pelas técnicas SAM e MTMF. A imagem Rule negada e a matched filter score foram coloridas e transformadas para o espaço de cores IHS (intensity-hue-saturation) sobre a banda três da cena ASTER. A classificação MTMF apresentou resultados superiores ao SAM para todas as áreas estudadas, uma vez que gerou mapas de distribuição de caulinita mais restritos, porém coincidentes com as anomalias de gasometria. Os resultados podem ser observados na figura 8 .

\section{Abundância de Caulinita}

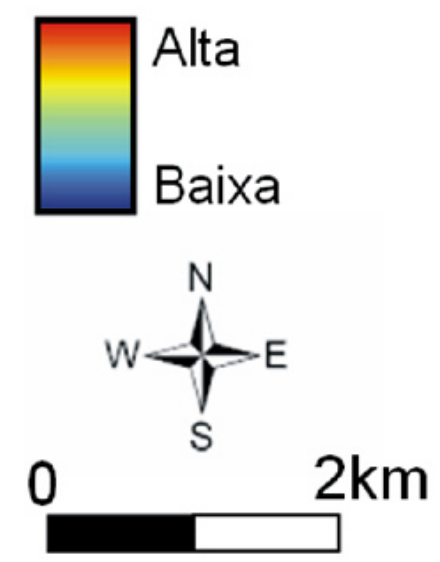

(b)

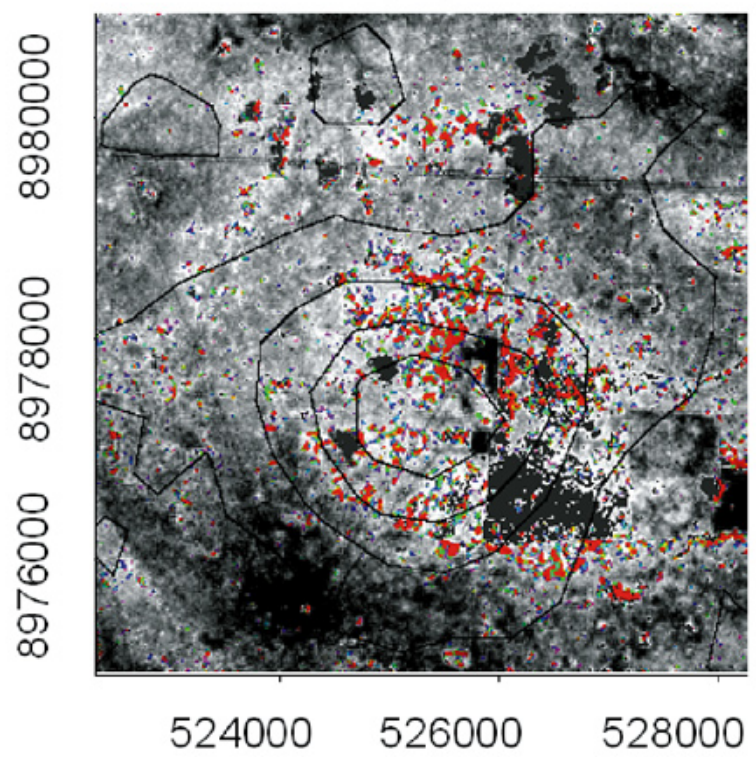

Figura 8 - Resultados da classificação Mixture Tuned Matched Filtering (MTMF) para (a) anomalia norte e (b) anomalia central com base em espectros de referência derivados de pontos na própria imagem e com altas concentrações de hidrocarbonetos; (c) resultado para a anomalia sul com base em espectro de referência derivado de amostra de campo do centro da anomalia. 
CLASSIFICAÇÃO POR REDES NEURAIS É relevante destacar que a experiência com as redes neurais do GeoXplore, da forma como aqui realizado, é pioneira, motivo pelo qual a compreensão do impacto da modificação de parâmetros de entrada nos resultados deve ser considerada com cautela. Os mapas de favo- rabilidade resultantes da classificação pelos sistemas Probabilistic Neural Network e Radial Basis Functional Link Network, apresentaram melhor discriminação dos pontos de acumulações de hidrocarbonetos detectados pela gasometria, em relação à classificação Fuzzy Clustering. Na figura 9 são apresentados os melhores
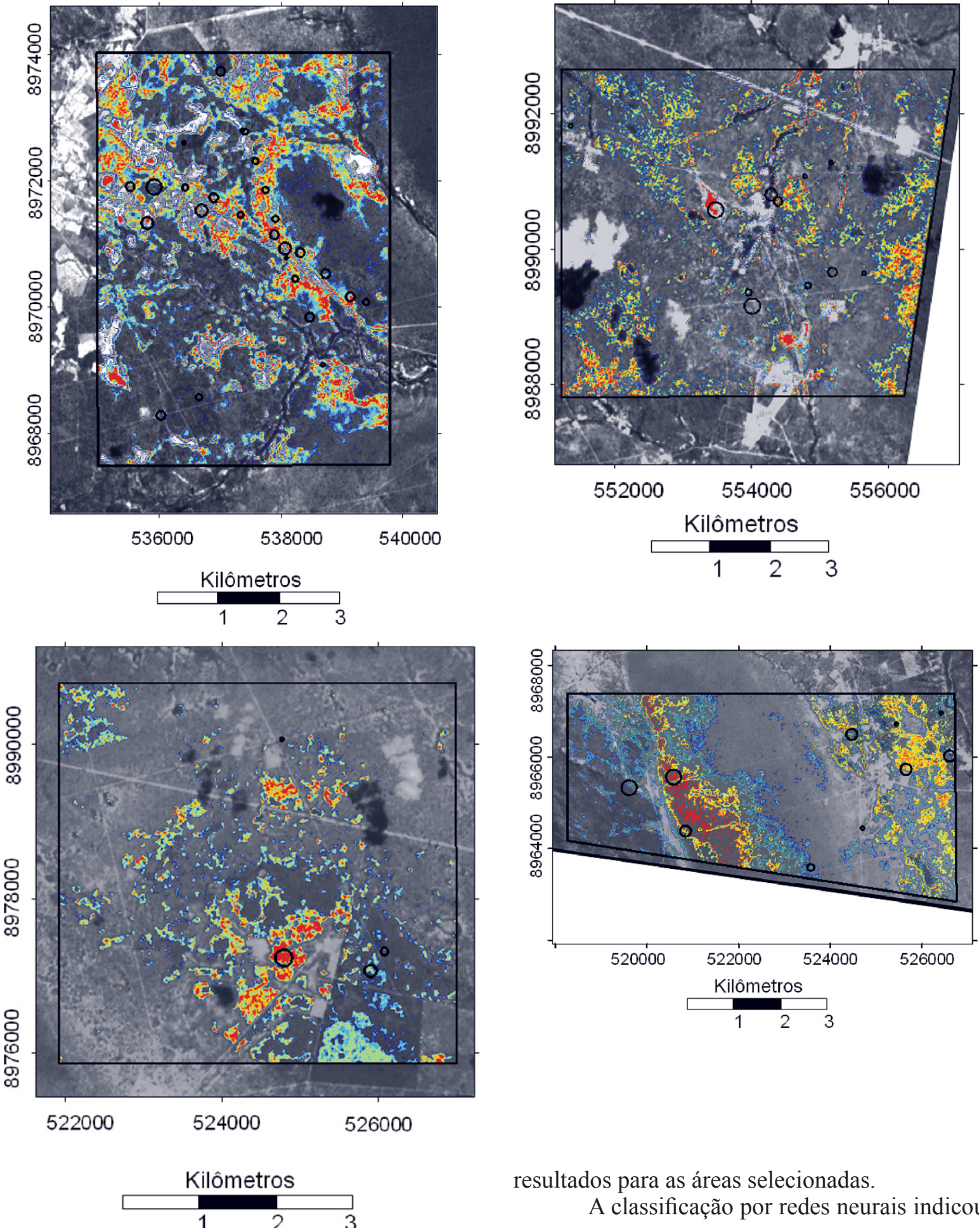

resultados para as áreas selecionadas.

A classificação por redes neurais indicou como

Figura 9 - Mapas de favorabilidade para a presença de hidrocarbonetos obtidos da classificação pelo sistema Radial Basis Functional Link Network (RBFLN) na anomalia sul (a) (coluna da esquerda, em cima) e norte (b) (coluna da direita, em cima) e pelo sistema Probabilistc Neural Network (PNN) na anomalia central (c) (coluna da esquerda, em baixo) e sudoeste (d) (coluna da esquerda, em baixo). A localização das áreas-alvo pode ser observada na figura 6. 
favoráveis regiões de contatos geológicos, lineamentos e drenagem, tal qual passível de observação na área norte e sul, e concordante com os resultados da interpolação dos dados de gasometria. Apesar de não ser destacado pelo processamento hiperespectral dos dados ASTER, as áreas de alta favorabilidade de acumulação de hidrocarbonetos indicadas pelas redes neurais incluem, particularmente, as cabeceiras dos rios; tal qual condizente com os modelos teóricos.

$\mathrm{Na}$ área sudoeste observa-se o contato litológico bacia/embasamento e a falha de Saité, ambos indicados pela gasometria como favoráveis para acumulação de hidrocarbonetos. As redes neurais, por sua vez, classificaram como favorável para hidrocarbonetos apenas a margem do contato inserida na bacia do Tucano Norte. Para a área sul, a anomalia no centro da krigagem, discriminada pela classificação hiperespectral e já descrita por Almeida-Filho et al. (2002a), foi também identificada pelas redes neurais. Para a área norte, as regiões de mais expressiva favorabilidade discriminadas pelas redes neurais foram igualmente mapeadas pela classificação hiperespectral da mesma imagem ASTER.

CONCLUSÕES Os resultados das técnicas estatísticas, com ênfase à tradicionalmente estabelecida krigagem dos dados de gasometria, mostrou-se bastante eficaz e possibilitou fácil visualização e avaliação da distribuição espacial das microexsudações. Por conseguinte, a correlação das acumulações de hidrocarbonetos com lineamentos estruturais, contatos litológicos e rede de drenagem foi demonstrada. Ademais, esses resultados funcionaram como guias para aplicação de outras técnicas de avaliação de ocorrências de HCs utilizadas neste estudo.

A análise por componentes principais das imagens ETM+/Landsat confirmou a presença de exsudação de hidrocarbonetos de acordo com o modelo de detecção estabelecido. Todas as áreas selecionadas para este processamento, as quais apresentaram altos valores de gasometria de hidrocarbonetos leves, mostraram concomitantemente ausência de vegetação fotossinteticamente ativa, ausência de compostos ricos em Fe-férrico, presença de compostos ricos Fe-ferroso e concentração de argilas.

A classificação hiperespectral da cena ASTER/ Terra, visando à identificação em especial da caulinita, possibilitada pela resolução espectral de tal sensor, foi também bastante satisfatória e concordante com o processamento da imagem ETM+/Landsat e com a krigagem. As melhores classificações, ou seja, as que ao mesmo tempo foram restritivas e incluíram os pontos geoquimicamente anômalos, foram as efetuadas pelo método Mixture Tuned Matched Filtering (MTMF) com endmembers de referência.

A classificação espectro-espacial das acumulações de hidrocarbonetos, realizada com procedimento pioneiro através do GeoXplore, foi efetuada por três diferentes sistemas de redes neurais sobre a imagem ASTER/Terra. Os resultados das classificações, em especial para os sistemas a Probabilistic Neural Network (PNN) e Radial Basis Functional Link Network (RBFLN), foram robustos e comparáveis aos resultados das classificações hiperespectrais. A classificação por redes neurais incluiu, majoritariamente, os pontos discriminados como anômalos pela gasometria e excluiu feições sabidamente não anômalas. Essas classificações apresentaram, ainda que em áreas restritas, correlação da alta favorabilidade à presença de hidrocarbonetos com feições estruturais e rede de drenagem, tal como evidenciado pela krigagem. Além disso, as classificações revelaram alvos potenciais para presença de exsudações e possivelmente reservas de hidrocarbonetos em regiões ainda sem estudos geoquímicos. Assim, o uso das redes neurais através do módulo GeoXplore, ainda que de forma experimental, provou tratar-se de metodologia adicional, rápida e eficiente para caracterização de feições em imagens ASTER/Terra relacionadas às microexsudações de hidrocarbonetos.

Agradecimentos Os autores agradecem à PETROBRAS, pela disponibilização dos dados de gasometria, e a Sérgio Sacani e Armando Zaupa Remacre pelo auxílio em Geoestatística. CR de Souza Filho agradece ao CNPq pela bolsa de Produtividade em Pesquisa.

\section{Referências}

Abrams M.J., Conel, J.E., Lang, H.R. 1984. The Joint NASA/ GEOSAT Test Case Project: Final Report. Oklahoma, EUA, AAPG, 996 p.

Abrams M., Hook S.J., Ramachandran B. 2002. ASTER User Handbook - Version 2, Jet Propulsion Laboratory, 135 p.

Almeida-Filho R., Miranda F.P., Yamakawa T. 1999. Remote detection of a tonal anomaly in an area of hydrocarbon microseepage, Tucano basin, north-eastern Brazil. International Journal of Remote Sensing, 20:2683-2688.

Almeida-Filho R. 2001. Processamento Digital de Imagens Landsat-TM na Deteç̧ão de Áreas de Microexsudação de Hidrocarbonetos, Região da Serra do Tonã, Bahia. In:
SBSR, 10, Foz de Iguaçu, Anais, p. 235-242.

Almeida-Filho R., Miranda F.P., Yamakawa T., Bueno G.V., Moreira F.R., Camargo E.G., Bentz C.M. 2002a. Data integration for a geologic model of hydrocarbon microseepage areas in the Tonã Plateau region, North Tucano basin, Brazil. Can. J. Remote Sensing, 28(1):96-107.

Almeida-Filho R. 2002b. Remote detection of hydrocarbon microseepage areas in the Serra do Tonã region, Tucano basin, Brazil. Can. J. Remote Sensing, 28(6):750-757.

Almeida-Filho R., Miranda F.P., Galvão L.S., Freitas C.C. 2002 c. Terrain chacteristics of a tonal anomaly remotely detected in an area of hydrocarbon microseepage, Tucano Basin, north-eastern Brazil. International Journal 
of Remote Sensing, 23(18):3893-3898.

Augusto V.A., Souza-Filho C.R., Almeida-Filho R. 2005. Caracterização de Exsudações de Hidrocarbonetos na Bacia do São Francisco-MG por meio de Imagens ASTER. In: Simpósio Brasileiro de Sensoriamento Remoto, 12, Goiânia, Anais, p. 1733-1740.

Barbosa J.S.F. \& Dominguez J.M.L. 1996. Geologia da Bahia. Texto Explicativo - Mapa Brasil 1:1000000, SGM, Salvador (BA), $400 \mathrm{p}$.

Boardman J.W. \& Kruse F.A. 1994. Automated spectral analysis: A geologic example using AVIRIS data, north Grapevine Mountains, Nevada. In: Environmental Research Institute of Michigan, Thematic Conference on Geological Remote Sensing, 10, Texas, p. 407-418.

Boardman J.W., Kruse F.A., Green R.O. 1995. Mapping target signatures via pratical unmixing of AVIRIS data. In: Jet Propulsion Laboratory, JPL Airbone Earth Science, 5, Summaries,95-1, p. 26-23.

Boardman J.W. 1998. Leveraging the High Dimensionality of AVIRIS Data for Improved Sub-Pixel Target Unmixing and Rejection of False Positives Mixture Tuned Matched Filtering. In: Jet Propulsion Laboratory, Annual JPL Airborne Geoscience Workshop, 7, Pasadena, Summaries, 97-21, 1, p. 55.

Buckingham W.F. \& Sommer S.E. 1983. Mineralogical characterization of rocks surfaces formed by hydrothermal alteration and weathering: application to remote sensing. Economic Geology, 78:664-674.

Bueno G.V. 1996. Serra do Tonã: um elo estratigráfico entre as bacias de Tucano Norte (BA) e Araripe (CE), nordeste do Brasil. In: Simpósio sobre o Cretáceo no Brasil, Rio Claro, Atas, p. 143-146.

Brown W.M., Gedeon T.D., Groves D.L., Barne R.G. 2000. Artificial neural networks: a new method for mineral prospectivity mapping. Australian Journal of Earth Science, 47(4):757-770.

Burnaman M.D. \& Withers K.D. 1995. Integration of Well and Seismic Data Using Geoestatistics In: Chambers R.L., Yarus J.M. (eds.) Stochastic Modeling and Geostatistics Principles, Methods and Case Studies. AAPG Computer Application in Geology, № 3, p. 177-199.

Chavez P.S.Jr. \& Kwarteng. A.Y. 1989. Selective Principal Component Analysis Photogram. Photogrammetric Engineering and Remote Sensing, 55(9):1163-1169.

Chiles J.P. \& Delfiner P. 1999. Geostatistics: modeling spatial uncertainty. New York, Wiley, Chichester. xi, 695 p.

Clarke R.H. \& Cleverly R.W. 1991. Petroleum seepage and post accumulation migration. In: England W.A. \& Fleet A.J. (eds.) Petroleum Migration. Geol. Soc. Sp. Publ., Geological Society of London, 59, p. 265-271.

Deutsch C.V. 2002. Geostatistical Reservoir Modeling. Applied Geostatistical Series, Oxford University Press, $376 \mathrm{p}$.

Donovan T.J., Forgey R.L., Roberts A.A. 1979. Aeromagnetic detection of diagenetic magnetite over oil field. $A A P G$ Bulletin, 63:245-248.

Donovan T.J., O’Brien D.P., Bryan J.G., Cunningham K.I. 1986. Near surface magnetic indicators of buried hydrocarbons: aeromagnetic detection and separation of spurious signals. In: Thematic Conference Remote Sensing for Exploration Geology, 5, Proceedings, vol. 1, p.: 219232.

Drury S. 2001. Image Interpretation in Geology. Reino Unido, Blacwell Science, 290 p.

Ducart D.F., Crósta A.P., Souza Filho C.R. Coniglio J. 2006. Alteration Mineralogy at the Cerro La Mina Epithermal Prospect, Patagonia, Argentina: Field Mapping, ShortWave Infrared Spectroscopy, and ASTER Images. Economic Geology and the Bulletin of the Society of Economic Geologists, 101:1010-1025.

ERSDAC Earth remote sensing data analysis center. 2001. The Crosstalk Correction Software: User's Guide. Mitsubishi Space Software Co., 17 p.

Goovaerts P. 1997. Geoestatistcs for Natural Resources Evaluation. New York, Oxford University Press, 483 p.

Green A.A., Berman M., Switzer P., Craig M.D. 1988. A transformation for ordering multispectral data in terms of image quality with implications for noise removal. IEEE Transactions on Geoscience and Remote Sensing, 26(1):65-74.

Hewitson B.C. \& Crane R.G. 1994. Neural Nets: Applications in Geography. Kluwer Acad. Publ. Ed, 194p.

Hunt G.A. 1991. Geological applications of reflected and emitted multispectral data over lateritised Archean terrain in western Australia. Tese de Doutoramento, Open University, Milton Keynes, Reino Unido, 402p.

Imspec. 2001. ACORN User's Guide. Analytical Imaging and Geophysics. Boulder, CO, USA, 64 p.

Iwasaki A., Fujisada H., Akao H., Shindou O., Akagi S. 2001. Enhancement of spectral separation performance for ASTER/SWIR. In: The International Society for Optical Engineering, SPIE, v. 4486, p. 42-50.

Kruse F.A., Lefkoff A.B., Boardman J.B., Heidebrecht K.B., Shapiro A.T., Barloon, P. J., e Goetz A.F.H. 1993. The Spectral Image Processing System (SIPS) - Interactive Visualization and Analysis of Imaging spectrometer Data. Remote Sensing of Environment, 44:145-163.

Looney C.G. \& Yu H. 2000. Special Software Development for Neural Network and Fuzzy Clustering Analysis in Geological Information Systems. Geological Survey of Canada, 34 p. Disponível em www.ige.unicamp.br/sdm/ ArcSDM3/documentation/dataxplore.pdf. Acessado em $\mathrm{jan} / 2007$.

Nobrega R.P. \& Souza-Filho C.R. 2003. Análise Espacial Guiada Pelos Dados (Data-Driven): O uso de Redes Neurais para Avaliação do Potencial Poli-Minerálico na região Centro-Leste da Bahia. Rev. Bras. de Geociências, 33(2):111-120.

Magnavita L, Destro N., Carvalho M. S. S., Milhomen P. S., Souza-Lima W. 2003. Bacia de Tucano. Fundação paleontológica PHOENIX. Ano 5. n52. Disponível em http:// www.phoenix.org.br/Phoenix52_Abr03.htm. Acessado em 16/05/2006.

Matthews M.D. 1986. Effects of hydrocarbon leakage on Earth surface materials. In: Symposium on Unconventional Methods in Exploration for Petroleum and Natural Gas, Proceedings, vol. 1, p. 27-44.

Medeiros V.C., Santos E.J., Santos C.A., Amorim J.L. 2000. Carta Geológica - Folha SC $24 X$ Aracaju NE. CPRM , Serviço Geológico do Brasil, Escala 1:500.000. 
Olea R.A. 1995. Fundamentals of Semivarigram Estimation, Modeling, and Usage. In: Chambers R.L. \& Yarus J.M. (eds.) Stochastic Modeling and Geostatistics Principles, Methods and Case Studies. AAPG Computer Application in Geology, no 3, p. 27-35.

Oliveira W.J. 1998. Caracterização das emanações gasosas de hidrocarbonetos na região do Remanso do Fogo $(M G)$, através do uso integrado de sensoriamento remoto, geoquímica, geofísica, geologia estrutural e espectrometria de reflectância. Tese de Doutoramento, Instituto de Geociências, Universidade Estadual de Campinas, $239 \mathrm{p}$.

Pontual S., Merry N., Gamson P. 1997. Spectral Interpretation Field Manual. G-MEX. AusSPpec International, $169 \mathrm{p}$.

Prost G. 1980. Alteration mapping with airbone multiespectral scanners. Economic Geology, 75:894-906.

Rojas E.H.M. 2004. Sintese Genética de Redes Neurais Artificiais ART2 na Classificação de Imagens ASTER para Mapeamento de Uso e Cobertura da Terra na Região Norte do Mato Grosso. Dissertação de Mestrado, Instituto Nacional de Pesquisas Espaciais, São José dos Campos - SP, 124 p.

Rolim J.L. 1984. Estudo da Seqüência Clástica e Carbonática da Serra do Tonã Macururé, Estado da Bahia. Tese de Doutoramento, Instituto de Geociências, Universidade Federal do Rio Grande do Sul, 155p.

Rouse J.W., Haas R.H., Schell J.A., Deering D.W., Harlan J.C. 1974. Monitoring the vernel advancement of ret- rogradation of natural vegetation. 1ed. Pasadena, JPL Publication (NASA/GSFC), $151 \mathrm{p}$.

Souza Filho C.R., Crósta A.P., Tapia C.H., Xavier R.P. 2007 (submetido). Mapping of Hydrothermal Alteration Zones at the Quellaveco Porphyry-Copper Deposit, Southern Peru, using Infrared Spectroscopy and Atmospherically Corrected ASTER Imagery Analysis. International Journal of Remote Sensing.

Schumacher D. 1996. Hydrocarbon-induced alteration of soils and sediments, In: Schumacher D. \& Abrams M.A. (eds.) Hydrocarbon Migration and its Near Surface Expression. AAPG Memoir 66, p. 71-89.

Schumacher D. 2002. Hydrocarbons Geochemical Exploration for Petroleum In: Schumacher D. \& Abrams M.A. (eds.) Hydrocarbon migration and its near-surface expression. AAPG, Memoir 66, p.184-204.

Thompson C.K., Saunders D.F., Burson K.R. 1994. Model advanced for hydrocarbon microseepage, related alterations. Oil \& Gas Journal. ABI/INFORM Global, 84:9599.

Van der Meer F., Van Dijk P., Van der Werff H., Yang, H. 2002. Remote Sensing and Petroleum Seepage: a review and case study. Terra Nova, 14(1):1-17.

Manuscrito ID 9427

Submetido em 02 setembro de 2007

Aceito em 01 de dezembro de 2007

Sistema eletrônico de submissão 